ARTICLE

\title{
Enantioselective synthesis of tertiary boronic esters through catalytic asymmetric reversed hydroboration
}

\author{
Tao-Tao Gao', Hou-Xiang Lu¹, Peng-Chao Gao ${ }^{1} \&$ Bi-Jie Li (iD ${ }^{1 凶}$
}

Chiral tertiary boronic esters are important precursors to bioactive compounds and versatile synthetic intermediates to molecules containing quaternary stereocenters. The development of conjugate boryl addition to $\alpha, \beta$-unsaturated amide has been hampered by the intrinsic low electrophilicity of the amide group. Here we show the catalytic asymmetric synthesis of enantioenriched tertiary boronic esters through hydroboration of $\beta, \beta$-disubstituted $\alpha, \beta$ unsaturated amides. The Rh-catalyzed hydroboration occurs with previously unattainable selectivity to provide tertiary boronic esters in high enantioselectivity. This strategy opens a door for the hydroboration of inert Michael acceptors with high stereocontrol and may provide future applications in the synthesis of biologically active molecules. 
T he organoboron compounds have found widespread applications in the design of functional materials and chemical sensors ${ }^{1,2}$. In addition, organoborons exhibit important biological properties, including antibacterial, anticancer, and antiviral activities 3,4 . These properties have spurred the development of novel therapeutic agents for drug discovery. Moreover, chiral, non-racemic organoboronates are valuable compounds in organic synthesis. A growing list of methods have been developed that enable stereospecific conversion of these compounds to a broad range of functionalized molecules ${ }^{5-11}$. Tertiary boronic esters are particularly attractive because they provide rapid access to quaternary stereocenters through subsequent transformations ${ }^{12-19}$.

Pioneering work from Yun ${ }^{20,21}$, Shibasaki ${ }^{22,23}$, Hoveyda ${ }^{16,24,25}$, and others ${ }^{26-31}$ have established metal-catalyzed boryl conjugate addition as a powerful method for the synthesis of chiral tertiary boronic esters. Starting from $\alpha, \beta$-unsaturated compounds, such as ketones and esters, tertiary boronic esters were generated in high enantioselectivities ${ }^{32-34}$. As one of the most important functional groups in organic chemistry, the amide group is ubiquitous in proteins, drugs, and pharmaceutically active compounds ${ }^{35,36}$. However, due to the intrinsic low electrophilicity of the amide group, the activity of $\alpha, \beta$-unsaturated amide is significantly lower as a Michael acceptor ${ }^{37-39}$. The delocalization of the nitrogen lone pair makes carboxamide the least electron-deficient carboxylic acid derivative. As a result, despite significant advances made in catalytic conjugate additions, currently there are only limited successful examples of catalytic asymmetric conjugate additions to simple $\alpha, \beta$-unsaturated amides ${ }^{40-46}$, and very few of them formed a quaternary stereocenter (Fig. 1a) ${ }^{47}$. In particular, metal-catalyzed boryl conjugate to simple unsaturated amides has been limited to the synthesis of secondary boronic ester ${ }^{30,48-51}$. There is one example for a copper-catalyzed enantioselective addition to acyclic $\beta, \beta$-disubstituted $\alpha, \beta$-unsaturated amide to form a tertiary boronic ester, in which a $\beta$-aryl group is necessary to activate the substrate (Fig. $1 b)^{52}$. Thus, catalytic asymmetric conjugate addition to inert $\alpha, \beta$-unsaturated amides to form quaternary stereocenters remains a significant challenge in asymmetric catalysis. A general protocol for catalytic asymmetric hydroboration of $\beta, \beta$-disubstituted $\alpha, \beta$-unsaturated amide to form a tertiary boronic ester remains undeveloped.

We surmised that a metal-catalyzed reversed hydroboration of $\beta, \beta$-disubstituted $\alpha, \beta$-unsaturated amide would provide an entry to address this challenge (Fig. 1c) $)^{53-56}$. In this strategy, a hydride is first incorporated at the a position followed by delivery of the boryl group at the $\beta$ position, which is mechanistically distinct from a boryl conjugate addition (vide infra). In this type of mechanism, the migratory insertion into the metal hydride by an alkene with low polarity may occur, thus overcoming the inherent low electrophilicity of $\alpha, \beta$-unsaturated amide. If the regioselectivity is effectively controlled and the enantioface of the alkene is successfully discriminated, this method would enable facile access to chiral tertiary boronic esters from inert $\alpha, \beta$-unsaturated amides.

However, we are aware of substantial challenges associated with this design. First, hydroboration of electron-deficient alkenes has been notoriously problematic. Due to the inherent electronic requirement, metal-catalyzed hydroboration of an $\alpha, \beta$-unsaturated compound affords a boron enolate ${ }^{57,58}$. This type of selectivity has long impeded the development of catalytic enantioselective hydroboration of widely existing electron-deficient alkenes. Second, in addition to the electronic requirement that favors the enolate formation, the steric hindrance at the $\beta$ position also prefers the addition of a small hydride at this site. The formation of a sterically hindered tertiary boronic ester is disfavored. Third, to obtain high enantioselectivity, the catalyst must a Conjugate addition to simple $\alpha, \beta$-unsaturated smide

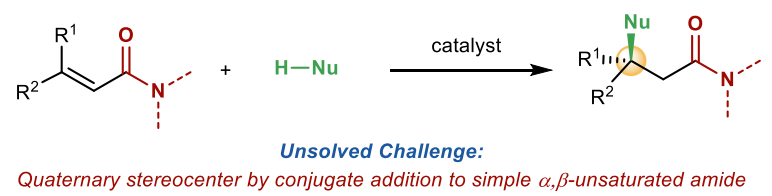

b Boryl conjugate addition

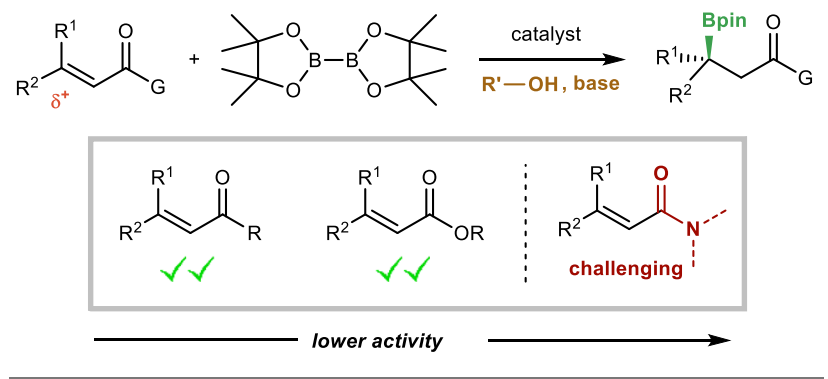

c Reversed hydroboration of $\alpha, \beta$-unsaturated amides (this work)

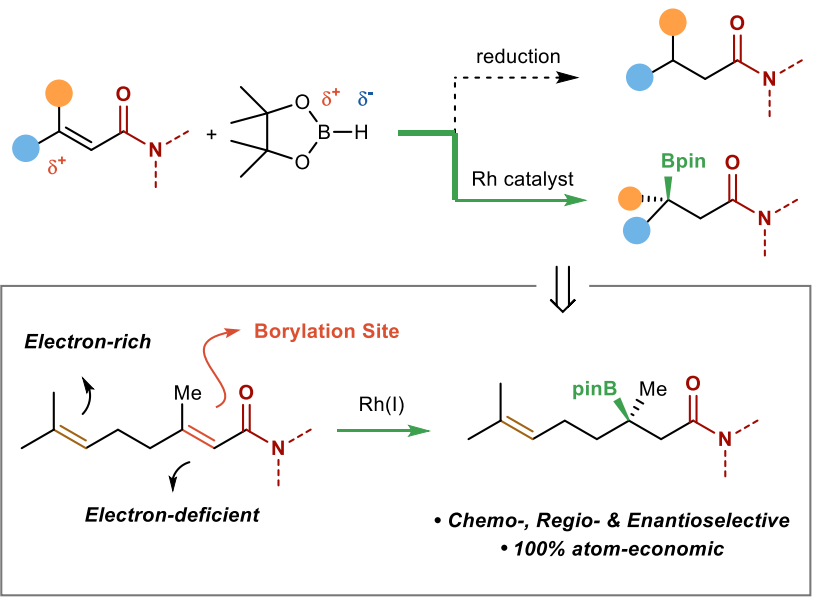

Fig. 1 Catalytic hydroboration of alkenes. a Conjugate addition to $\alpha, \beta$ unsaturated amides. b Boryl conjugate addition. c Reversed hydroboration of $\alpha, \beta$-unsaturated amides.

be able to differentiate between two similar alkyl groups at the $\beta$ position in the acyclic system. Therefore, in order to achieve the hydroboration of $\beta, \beta$-disubstituted $\alpha, \beta$-unsaturated amide, the catalyst must exert substantial control to override both the electronic and steric preferences, and to obtain high enantioselectivity.

We report here a catalytic asymmetric hydroboration of inert $\alpha, \beta$-unsaturated amides to construct tertiary boronic esters. The catalyst system we developed is able to (1) reverse the inherent electronic requirement of a hydroboration process, (2) overcome the steric hindrance at the disubstituted $\beta$ position, and (3) distinguish between the similar steric size of the two $\beta$ substituents. Starting from easily available materials, this atom-economic process provides a facile method to generate tertiary boronic esters with high regio- and enantioselectivities. This strategy opens a door for the catalytic conjugate addition of inert disubstituted $\alpha, \beta$-unsaturated amide to generate quaternary stereocenters.

\section{Results and discussion}

Reaction development. To take advantage of amide as a key designing element ${ }^{59-63}$, we began our study by testing the hydroboration of $1 \mathrm{a}$ and pinacolborane (HBpin; Table 1). In the 


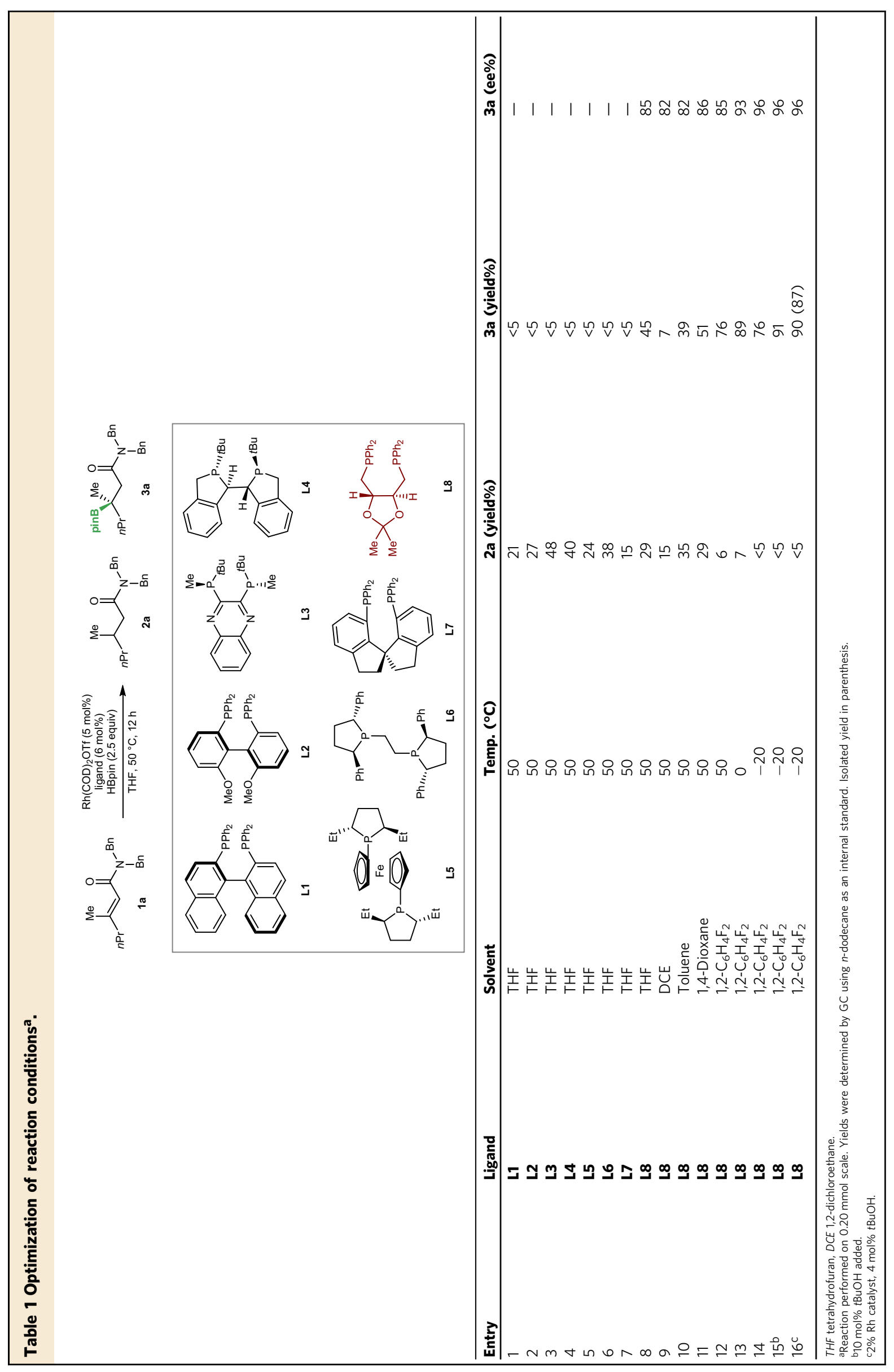



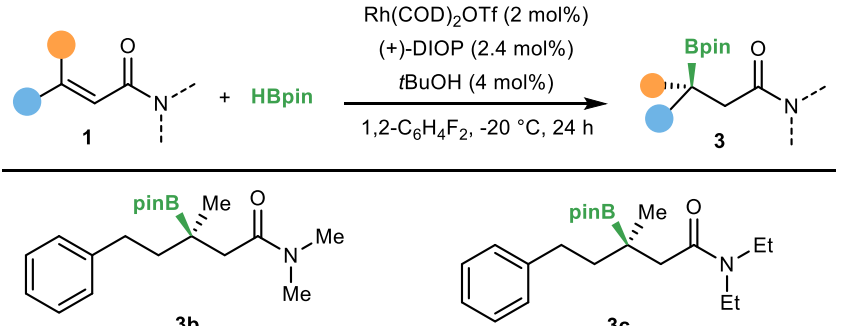

3b
$54 \%, 93 \%$ ee
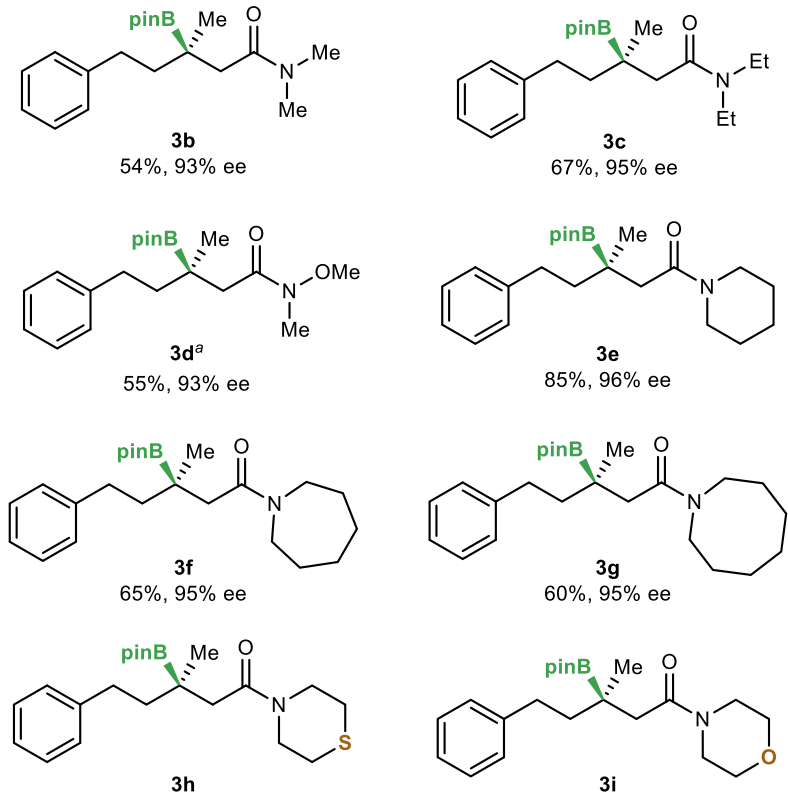

$52 \%, \stackrel{3 h}{99} \%$ ee

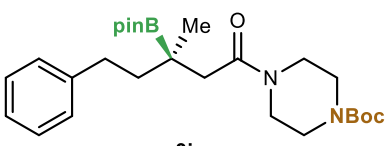

$70 \%, \stackrel{3 \mathbf{j}}{92} \%$ ee

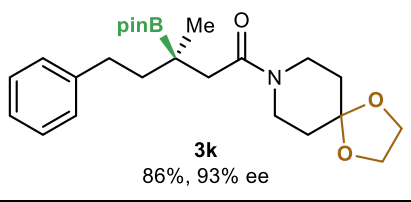

Fig. 2 Amide scope. Reversed hydroboration of $N$-substituted $\alpha, \beta$ unsaturated amide. ${ }^{a}$ The product was isolated after oxidation. Boc $t$ butyloxy carbonyl.

presence of $\mathrm{Rh}(\mathrm{COD})_{2} \mathrm{OTf}$, a series of chiral ligands were tested. However, only the reduction product (2a) was detected (entries 1-7). After substantial effort, we found that in the presence of (+)-DIOP ligand L8 (entry 8$)^{64}$, the reversed hydroboration product $3 \mathbf{a}$ was obtained in $45 \%$ yield together with reduction product. In addition, the tertiary boronic ester was formed in good enantioselectivity. Subsequently, various solvents were tested (entries 9-12). When the reaction was conducted in 1,2difluorobenzene, the selectivity was improved, favoring the formation of 3a. Lowering the reaction temperature to $0{ }^{\circ} \mathrm{C}$ led to an increase ee of $93 \%$ (entry 13). Further lowering the temperature to $-20{ }^{\circ} \mathrm{C}$ increased the enantioselectivity and suppressed the undesired reduction product (entry 14). Interestingly, the addition of catalytic amount of tert-butanol $(t \mathrm{BuOH})$ further improved the yield (entry 15), although its role in the reaction is still unclear (see the Supplementary information). Lowering the catalyst loading to $2 \mathrm{~mol} \%$ did not affect the yield (entry 16).

Reaction scope. With this simple yet effective conditions in hand, we investigated the scope of various $\alpha, \beta$-unsaturated amides. As summarized in Fig. 2, $\alpha, \beta$-unsaturated amides derived from a variety of amines underwent the reversed hydroboration to give tertiary boronic esters in good yields and high enantioselectivities. The reaction is applicable to substrates derived from both acyclic amines (3b-3d) and cyclic amines (3e-3k). The successful hydroboration of Weinreb amide (3d) provides an opportunity to access ketone product. Functional groups, including sulfur, ether, carbamate, and acetal, were compatible with this system $(\mathbf{3 h}-\mathbf{3 k})$. However, hydroboration of $\alpha, \beta$-unsaturated secondary amide with a free $\mathrm{NH}$ group did not provide any desired product.

Next, we sought to explore the reversed hydroborations of various $\beta$-disubstituted $\alpha, \beta$-unsaturated amides (Fig. 3). A series of $\beta$-disubstituted $\alpha, \beta$-unsaturated amides underwent regioselective hydroboration to afford the corresponding products in good yields and high enantioselectivities. Aryl and alkyl halide, ether, silyl ether, ester, and heteroarenes were well compatible with the catalytic system (31-3y). The absolute configurations of compounds $\mathbf{3 n}$ and $\mathbf{3 o}$ were unambiguously confirmed by X-ray crystallography. In addition, the reaction is highly chemoselective, as demonstrated by the preferential reaction of electron-deficient alkene in the presence of electron-rich ones (3z, 3aa). Furthermore, the catalyst system tolerated not only $\beta$-methyl substituent, but also larger ethyl and propyl groups (3ab, 3ac). Importantly, the high enantioselectivities obtained by $\mathbf{3 a d}$ and 3ae highlighted the ability of the catalyst to differentiate quite similar groups. However, the attempts to form vicinal quaternary and tertiary stereocenters failed despite significant efforts, likely because of the increased steric hindrance (3af, 3ag).

The synthetic utility of this reversed hydroboration was further probed by the reactions of amides derived from drug molecules. Hydroboration of $\alpha, \beta$-unsaturated amides derived from tomoxetine, paroxetine, and duloxetine generated the products with high diastereoselectivities (3ah, 3ai, 3aj), no racemization occurred for the existing stereocenters. In addition, the stereoisomers of $\mathbf{3 a h}, \mathbf{3 a i}, \mathbf{3 a j}$ were also obtained with high diastereoselectivities, respectively, when we use (-)-DIOP as the ligand.

Transformation of products. The resulting reversed hydroboration products could be further transformed to a series of functional groups (Fig. 4). For example, enantioenriched tertiary alcohol 4 could be obtained by stereospecific oxidation of the boron compound $3 \mathbf{i}$. Treatment of $3 \mathbf{i}$ with $\mathrm{KHF}_{2}$ yields the potassium trifluoroborate salt 5 in $83 \%$ yield. In addition, tertiary boronic esters underwent $\mathrm{C}-\mathrm{C}$ bond formation with vinyl Grignard or aryl lithium reagent to afford vinylation and arylation compounds 6 and 7 bearing an all-carbon quaternary stereocenter in high enantioselectivities, respectively. Finally, a homologation of the tertiary boronic ester occurred without erosion of the enantioselectivity (8).

Mechanistic studies. To gain insight into the reaction mechanism, a series of control experiments were performed. First, when $\alpha, \beta$-unsaturated ester 9 was used, no reversed hydroboration product 9a was observed under the standard reaction conditions (Fig. 5a). Thus, the coordinating ability of an amide group plays a crucial role in reaction system. To probe the possibility of a reaction sequence involving alkene isomerization followed by directed alkene hydroboration, catalytic hydroboration of $\beta, \gamma$ unsaturated amides $\mathbf{1 0}$ and $\mathbf{1 1}$ were conducted. No hydroboration product was observed when using $\beta, \gamma$-unsaturated amide 10 (Fig. 5b). In addition, the hydroboration of $\beta, \gamma$-unsaturated amide 11 occurred preferentially at the $\gamma$ position (Fig. $5 \mathrm{c}$ ). The $\beta$ boration product $3 \mathbf{i}$ was obtained in low yield and, more importantly, opposite sense of enantioselectivity. These results provide evidence that the reverse hydroboration occurs directly with $\alpha, \beta$-unsaturated amides without prior isomerization.

Computational studies. Computational studies provided information of the energy of each step in the catalytic cycle (Fig. 6). Oxidative addition of HBpin to the amide bound rhodium complex (Int-1) generates a five-coordinated rhodium hydride 


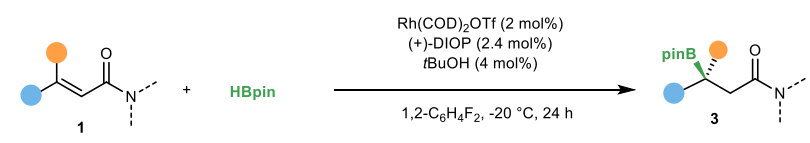

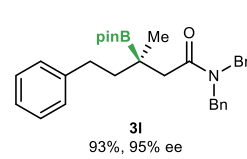<smiles>Cc1ccc(CCC(C)(C)CC(=O)N2CCOCC2)cc1</smiles>

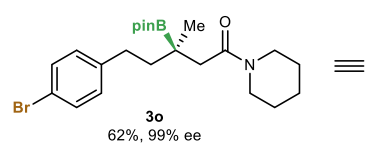

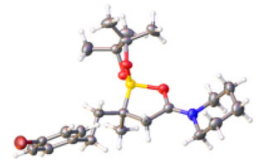

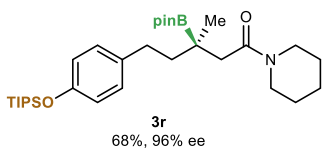<smiles>COc1ccc(CCC(C)C(=O)N2CCCCC2)cc1</smiles>
${ }_{83 \%,}^{35}, 96 \%$ ee<smiles>CC(C)CC(CC(=O)N1CCCCC1)Cc1ccco1</smiles>
$66 \%, 93 \%$ oe

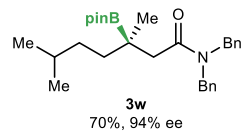

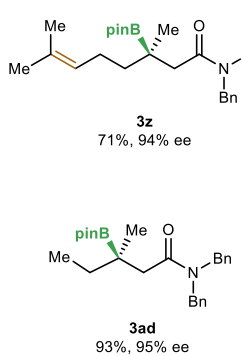

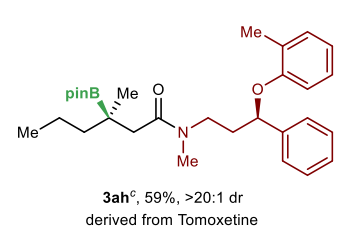<smiles>CCC[C@H](C)C[C@H](C)C(=O)N(I)CCC(Oc1ccccc1I)c1ccccc1</smiles>

$3 \mathbf{a k}^{d}, 61 \%,>20: 1 \mathrm{dr}$ derived from Tomoxetine

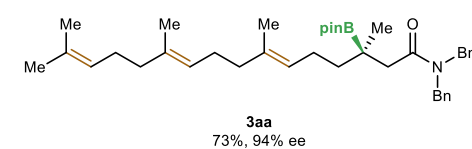<smiles>CC(C)CC(C)(C)CC(C)(C)CCCc1ccccc1</smiles>

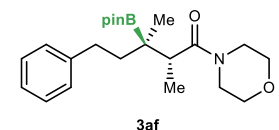
${ }_{<5 \%}^{3 a f}$

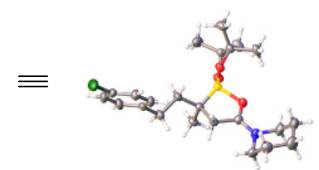<smiles>COc1ccc(CCC2CC(C(=O)N3CCCCC3)C2)cc1</smiles>
$68 \%, 94 \%$ ee

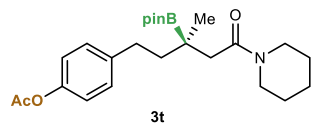
$67 \%$, $98 \%$ ee<smiles></smiles>

$70 \%, 97 \%$ ee

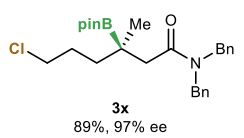

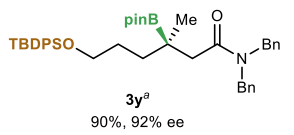

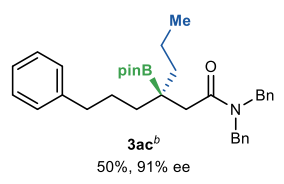

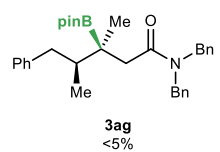

Fig. 3 Substrate scope. Reversed hydroboration of $\beta, \beta$-disubstituted $\alpha, \beta$-unsaturated amide. ${ }^{a} 5$ mol\% Rh catalyst. b7.5 mol\% Rh catalyst, 3.5 equivalent of HBpin, $0^{\circ} \mathrm{C}$. The product was isolated after oxidation. ${ }^{\circ} 5 \mathrm{~mol} \% \mathrm{Rh}$ catalyst. The product was isolated after oxidation. ${ }^{\mathrm{d}} 5 \mathrm{~mol} \% \mathrm{Rh}$ catalyst, $6.0 \mathrm{~mol} \%$ (-)-DIOP. The product was isolated after oxidation. TIPS triisopropylsilyl, MOM methoxymethyl, TBDPS t-butyldiphenylsilyl.

(Int-2). After migratory insertion of the alkene into the rhodium hydride, an alkyl rhodium complex (Int-3) is formed, in which the amide is coordinated to the metal center. Finally, C-B forming reductive elimination delivers the hydroboration product and regenerates the catalyst through ligand exchange. The calculated energies suggest that the migratory insertion is irreversible and determines the enantioselectivity.

To further understand the origin of enantioselectivity, the energies of different transition states for migration insertion were computed (Fig. 7). The lowest energy pathway leading to the $S$ enantiomer has an activation barrier of $21.0 \mathrm{kcal} / \mathrm{mol}$ (TS-2), while the lowest energy pathway leading to the $R$ enantiomer has an activation barrier of $23.4 \mathrm{kcal} / \mathrm{mol}$ (TS-2'). The energy difference between TS-2 and TS-2' $(2.4 \mathrm{kcal} / \mathrm{mol})$ correlates with the major enantiomer observed in experiments. In TS-2', the $\alpha, \beta$ unsaturated amide coordinates to rhodium through the opposite enantioface to that in TS-2. In TS-2, the phenyl group on the phosphine atom of the ligand forms two attractive $\mathrm{CH}^{\cdots} \mathrm{O}$ interaction with the carbonyl group of the substrate $\left(\mathrm{CH}^{\cdots} \mathrm{O}\right.$ distance 2.26 and $2.45 \AA$, respectively ${ }^{65,66}$. In contrast, such interaction is not observed in TS-2 ${ }^{\prime}$ due to the orientation of the carbonyl group. In addition, the phenyl group on the ligand 
<smiles>C[C@@](O)(CCc1ccccc1)CC(=O)N1CCOCC1</smiles><smiles>C[C@](CCCc1ccccc1)(CC(=O)[O-])CC(=O)N1CCOCC1</smiles><smiles>CCC</smiles>

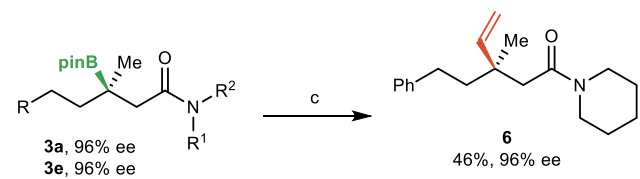
$3 \mathrm{e}, 96 \%$ e<smiles>CCCCCCC</smiles><smiles>CCC[C@](CO)(CC(=O)N(Cc1ccccc1)Cc1ccccc1)CC(C)(C)C</smiles><smiles>COc1cc(OC)cc(C(C)(CCO)CC(=O)N(Cc2ccccc2)Cc2ccccc2)c1</smiles>

Fig. 4 Synthetic utility. Further transformations of the hydroboration products. Reaction conditions: a $\mathrm{NaBO}_{3}, \mathrm{H}_{2} \mathrm{O}$, THF; b $\mathrm{KHF}_{2}, \mathrm{MeCN}, \mathrm{H}_{2} \mathrm{O}$; c (1) vinylMgBr, THF, r.t; (2) $\mathrm{I}_{2}, \mathrm{MeOH},-78^{\circ} \mathrm{C}$; (3) $\mathrm{NaOMe}, \mathrm{MeOH}$; d (1) 1bromo-3,5-dimethoxybenzene, tBuLi, THF, $-78^{\circ} \mathrm{C}$; (2) NBS, THF, $-78^{\circ} \mathrm{C}$; e (1) $\mathrm{ClCH}_{2} \mathrm{I}, n \mathrm{BuLi}, \mathrm{THF},-78^{\circ} \mathrm{C}$; (2) $\mathrm{H}_{2} \mathrm{O}_{2}, \mathrm{NaOH}, \mathrm{MeOH}, \mathrm{H}_{2} \mathrm{O}$.

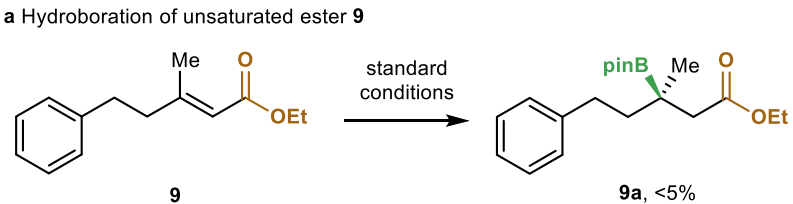

b Hydroboration of unsaturated amide 10<smiles>CC(=CCC(=O)N1CCOCC1)CCc1ccccc1</smiles>

10

c Hydroboration of unsaturated amide 11<smiles>C=C(CCc1ccccc1)CC(=O)N1CCOCC1</smiles>

$3 \mathbf{i}$

$12 \%,-70 \%$ ee

Fig. 5 Control experiments. a Hydroboration of unsaturated ester $\mathbf{9}$. b Hydroboration of unsaturated amide 10. $\mathbf{c}$ Hydroboration of unsaturated amide $\mathbf{1 1 .}$

compels the substrate in a way that the ethyl group experiences significant repulsion with the $N$-methyl group (TS-2'). Therefore, the $\mathrm{CH} \cdots \mathrm{O}$ interaction with the phenyl group on the ligand in TS-2 and the repulsive interaction in TS- $2^{\prime}$ contributes to the relative energies of these transition states, and leads to the high enantioselectivity observed.

In summary, we have developed a Rh-catalyzed asymmetric reversed hydroboration to construct chiral tertiary boronic esters.

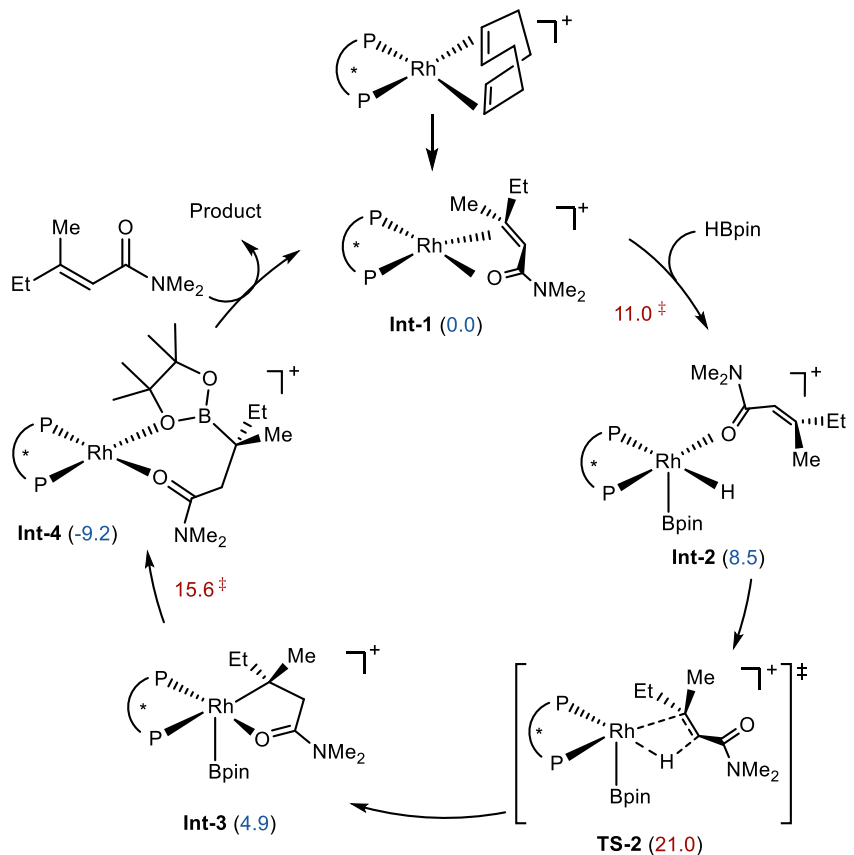

Fig. 6 Proposed mechanism. Catalytic cycle with computed free energies of transition states (red) and intermediates (blue) in $\mathrm{kcal} / \mathrm{mol}$.
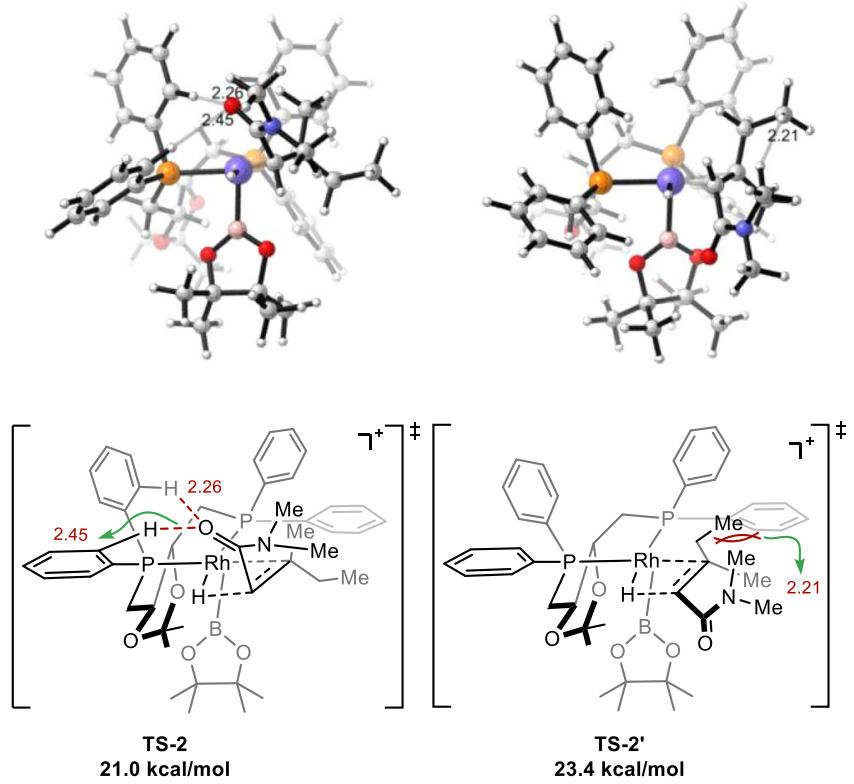

Fig. 7 Structures of competing transition states. Transition state structures leading to major enantiomer (TS-2) and minor enantiomer (TS-2' ${ }^{\prime}$.

Using a catalyst formed from cationic rhodium and DIOP ligand, hydroboration of $\beta, \beta$-disubstituted $\alpha, \beta$-unsaturated amides delivers chiral tertiary boronic esters with high regioselectivity and enantioselectivity. Computation studies revealed the origin of enantioselectivity. Further mechanistic studies and application of this methodology is ongoing in our laboratory.

\section{Methods}

General procedure for the catalytic hydroboration. In an Ar-filled glovebox, the $\alpha, \beta$-unsaturated amide ( $0.25 \mathrm{mmol}, 1.0$ equiv.), $\mathrm{Rh}(\mathrm{COD}){ }_{2} \mathrm{OTf}(2.3 \mathrm{mg}, 2.0 \mathrm{~mol} \%)$, and (+)-DIOP (3.0 mg, $2.4 \mathrm{~mol} \%)$ were weighed into a one-dram screw-capped vial. Subsequently, 1,2 -difluorobenzene $(2.5 \mathrm{~mL}), t \mathrm{BuOH}(4.0 \mathrm{~mol} \%)$, and pinacolborane ( $80.0 \mathrm{mg}, 2.5$ equiv.) were added via syringes. The vial was capped with a 
Teflon-lined screw cap, and the reaction was then removed from the glovebox and stirred at $-20^{\circ} \mathrm{C}$ for $24 \mathrm{~h}$. Then the solution was concentrated under reduced pressure. After removal of the solvent, the crude product was analyzed by ${ }^{1} \mathrm{H}$ NMR and purified by column chromatography on silica gel with EtOAc/hexanes mixture as eluent.

Reporting summary. Further information on research design is available in the Nature Research Reporting Summary linked to this article.

\section{Data availability}

The authors declare that all the data supporting the findings of this research are available within the article and its Supplementary Information. Crystallographic data of compounds $\mathbf{3 n}$ and 3o data have been deposited in the Cambridge Crystallographic Data Center under accession number CCDC: 2031005 and 2031762.

Received: 27 January 2021; Accepted: 28 May 2021;

Published online: 18 June 2021

\section{References}

1. Mellerup, S. K. \& Wang, S. Boron-based stimuli responsive materials. Chem. Soc. Rev. 48, 3537-3549 (2019).

2. Bull, S. D. et al. Exploiting the reversible covalent bonding of boronic acids: recognition, sensing, and assembly. Acc. Chem. Res 46, 312-326 (2013).

3. Smoum, R., Rubinstein, A., Dembitsky, V. M. \& Srebnik, M. Boron containing compounds as protease inhibitors. Chem. Rev. 112, 4156-4220 (2012).

4. Touchet, S., Carreaux, F., Carboni, B., Bouillon, A. \& Boucher, J.-L. Aminoboronic acids and esters: from synthetic challenges to the discovery of unique classes of enzyme inhibitors. Chem. Soc. Rev. 40, 3895-3914 (2011).

5. Leonori, D. \& Aggarwal, V. K. Stereospecific couplings of secondary and tertiary boronic esters. Angew. Chem. Int. Ed. 54, 1082-1096 (2015).

6. Collins, B. S. L., Wilson, C. M., Myers, E. L. \& Aggarwal, V. K. Asymmetric synthesis of secondary and tertiary boronic esters. Angew. Chem., Int. Ed. 56, 11700-11733 (2017).

7. Wang, M. \& Shi, Z. Methodologies and strategies for selective borylation of C-Het and C-C bonds. Chem. Rev. 120, 7348-7398 (2020).

8. Reyes, R. L. et al. Asymmetric remote $\mathrm{C}-\mathrm{H}$ borylation of aliphatic amides and esters with a modular iridium catalyst. Science 369, 970 (2020).

9. Scott, H. K. \& Aggarwal, V. K. Highly enantioselective synthesis of tertiary boronic esters and their stereospecific conversion to other functional groups and quaternary stereocentres. Chem. Eur. J. 17, 13124-13132 (2011).

10. Matteson, D. S. Boronic esters in asymmetric synthesis. J. Org. Chem. 78, 10009-10023 (2013).

11. Sandford, C. \& Aggarwal, V. K. Stereospecific functionalizations and transformations of secondary and tertiary boronic esters. Chem. Commun. 53, 5481-5494 (2017).

12. Stymiest, J. L., Bagutski, V., French, R. M. \& Aggarwal, V. K. Enantiodivergent conversion of chiral secondary alcohols into tertiary alcohols. Nature $\mathbf{4 5 6}$, 778-782 (2008).

13. Guzman-Martinez, A. \& Hoveyda, A. H. Enantioselective synthesis of allylboronates bearing a tertiary or quaternary B-substituted stereogenic carbon by NHC-Cu-catalyzed substitution reactions. J. Am. Chem. Soc. 132, 10634-10637 (2010).

14. Pulis, A. P., Blair, D. J., Torres, E. \& Aggarwal, V. K. Synthesis of enantioenriched tertiary boronic esters by the lithiation/borylation of secondary alkyl benzoates. J. Am. Chem. Soc. 135, 16054-16057 (2013).

15. Hong, K., Liu, X. \& Morken, J. P. Simple access to elusive $\alpha$-boryl carbanions and their alkylation: an umpolung construction for organic synthesis. J. Am. Chem. Soc. 136, 10581-10584 (2014).

16. Radomkit, S. \& Hoveyda, A. H. Enantioselective synthesis of boronsubstituted quaternary carbon stereogenic centers through NHC-catalyzed conjugate additions of (pinacolato)boron units to enones. Angew. Chem. Int. Ed. 53, 3387-3391 (2014).

17. $\mathrm{Hu}, \mathrm{N}$. et al. Synthesis of chiral $\alpha$-amino tertiary boronic esters by enantioselective hydroboration of $\alpha$-arylenamides. J. Am. Chem. Soc. 137, 6746-6749 (2015).

18. Shoba, V. M., Thacker, N. C., Bochat, A. J. \& Takacs, J. M. Synthesis of chiral tertiary boronic esters by oxime-directed catalytic asymmetric hydroboration. Angew. Chem. Int. Ed. 55, 1465-1469 (2016).

19. Chakrabarty, S. \& Takacs, J. M. Synthesis of chiral tertiary boronic esters: phosphonate-directed catalytic asymmetric hydroboration of trisubstituted alkenes. J. Am. Chem. Soc. 139, 6066-6069 (2017).

20. Lee, J.-E. \& Yun, J. Catalytic asymmetric boration of acyclic $\alpha, \beta$-unsaturated esters and nitriles. Angew. Chem. Int. Ed. 47, 145-147 (2008).
21. Feng, X. \& Yun, J. Conjugate boration of $\beta, \beta$-disubstituted unsaturated esters: asymmetric synthesis of functionalized chiral tertiary organoboronic esters. Chem. Eur. J. 16, 13609-13612 (2010).

22. Chen, I. H., Yin, L., Itano, W., Kanai, M. \& Shibasaki, M. Catalytic asymmetric synthesis of chiral tertiary organoboronic esters through conjugate boration of $\beta$-substituted cyclic enones. J. Am. Chem. Soc. 131, 11664-11665 (2009)

23. Chen, I. H., Kanai, M. \& Shibasaki, M. Copper(I)-secondary diamine complex-catalyzed enantioselective conjugate boration of linear $\beta, \beta$ disubstituted enones. Org. Lett. 12, 4098-4101 (2010).

24. O’Brien, J. M., Lee, K.-s \& Hoveyda, A. H. Enantioselective synthesis of boronsubstituted quaternary carbons by $\mathrm{NHC}-\mathrm{Cu}$-catalyzed boronate conjugate additions to unsaturated carboxylic esters, ketones, or thioesters. J. Am. Chem. Soc. 132, 10630-10633 (2010).

25. Wu, H., Radomkit, S., O’Brien, J. M. \& Hoveyda, A. H. Metal-free catalytic enantioselective $\mathrm{c}-\mathrm{b}$ bond formation: (pinacolato)boron conjugate additions to $\alpha, \beta$-unsaturated ketones, esters, weinreb amides, and aldehydes promoted by chiral N-heterocyclic carbenes. J. Am. Chem. Soc. 134, 8277-8285 (2012)

26. Lawson, Y. G. et al. Platinum catalysed 1,4-diboration of $\alpha, \beta$-unsaturated ketones. Chem. Commun. 33, 2051-2052 (1997).

27. Ito, H., Yamanaka, H., Tateiwa, J.-I. \& Hosomi, A. Boration of an $\alpha, \beta$-enone using a diboron promoted by a copper(I)-phosphine mixture catalyst. Tetrahedron Lett. 41, 6821-6825 (2000).

28. Kubota, K., Hayama, K., Iwamoto, H. \& Ito, H. Enantioselective borylative dearomatization of indoles through copper(I) catalysis. Angew. Chem. Int. Ed. 54, 8809-8813 (2015).

29. Takahashi, K., Ishiyama, T. \& Miyaura, N. Addition and coupling reactions of bis(pinacolato)diboron mediated by $\mathrm{CuCl}$ in the presence of potassium acetate. Chem. Lett. 29, 982-983 (2000).

30. Shiomi, T., Adachi, T., Toribatake, K., Zhou, L. \& Nishiyama, H. Asymmetric $\beta$-boration of $\alpha, \beta$-unsaturated carbonyl compounds promoted by chiral rhodium-bisoxazolinylphenyl catalysts. Chem. Commun. 45, 5987-5989 (2009).

31. Lillo, V., Geier, M. J., Westcott, S. A. \& Fernández, E. Ni and Pd mediate asymmetric organoboron synthesis with ester functionality at the $\beta$-position. Org. Biomol. Chem. 7, 4674-4676 (2009).

32. Schiffner, J. A., Müther, K. \& Oestreich, M. Enantioselective conjugate borylation. Angew. Chem. Int. Ed. 49, 1194-1196 (2010)

33. Calow, A. D. J. \& Whiting, A. Catalytic methodologies for the $\beta$-boration of conjugated electron deficient alkenes. Org. Biomol. Chem. 10, 5485-5497 (2012).

34. Chen, J.-B. \& Whiting, A. Recent advances in copper-catalyzed asymmetric hydroboration of electron-deficient alkenes: methodologies and mechanism. Synthesis 50, 3843-3861 (2018)

35. Bray, B. L. Large-scale manufacture of peptide therapeutics by chemical synthesis. Nat. Rev. Drug Discov. 2, 587-593 (2003).

36. Valeur, E. \& Bradley, M. Amide bond formation: beyond the myth of coupling reagents. Chem. Soc. Rev. 38, 606-631 (2009).

37. Vicario, J. L. R. E, Carrillo, L \& Uria, U. Organocatalytic Asymmetric Nucleophilic Addition to Electron-Deficient Alkenes, 119-188 (Wiley-VCH, 2014).

38. Rodríguez-Fernández, M., Yan, X., Collados, J. F., White, P. B. \& Harutyunyan, S. R. Lewis acid enabled copper-catalyzed asymmetric synthesis of chiral $\beta$-substituted amides. J. Am. Chem. Soc. 139, 14224-14231 (2017).

39. Li, Y.-B., Tian, H. \& Yin, L. Copper(I)-catalyzed asymmetric 1,4-conjugate hydrophosphination of $\alpha, \beta$-unsaturated amides. J. Am. Chem. Soc. 142, 20098-20106 (2020)

40. Mauduit, M. B. O, Clavier, H, Crévisy, C \& Denicourt-Nowicki, A. MetalCatalyzed Asymmetric Nucleophilic Addition to Electron-Deficient Alkenes, 189-341 (Wiley-VCH, 2014).

41. Heravi, M. M., Dehghani, M. \& Zadsirjan, V. Rh-catalyzed asymmetric $1,4-$ addition reactions to $\alpha, \beta$-unsaturated carbonyl and related compounds: an update. Tetrahedron. Asymmetry 27, 513-588 (2016).

42. Sakuma, S. \& Miyaura, N. Rhodium(I)-catalyzed asymmetric 1,4-addition of arylboronic acids to $\alpha, \beta$-unsaturated amides. J. Org. Chem. 66, 8944-8946 (2001).

43. Suzuki, H., Sato, I., Yamashita, Y. \& Kobayashi, S. Catalytic asymmetric directtype 1,4-addition reactions of simple amides. J. Am. Chem. Soc. 137, 4336-4339 (2015)

44. Nemoto, T. et al. Catalytic asymmetric epoxidation of $\alpha, \beta$-unsaturated amides: efficient synthesis of $\beta$-aryl $\alpha$-hydroxy amides using a one-pot tandem catalytic asymmetric epoxidation-pd-catalyzed epoxide opening process. $J$. Am. Chem. Soc. 124, 14544-14545 (2002).

45. Hatano, M., Horibe, T. \& Ishihara, K. Chiral magnesium(II) binaphtholates as cooperative brønsted/lewis acid-base catalysts for the highly enantioselective addition of phosphorus nucleophiles to $\alpha, \beta$-unsaturated esters and ketones. Angew. Chem. Int. Ed. 52, 4549-4553 (2013). 
46. Yasukawa, T., Saito, Y., Miyamura, H. \& Kobayashi, S. Chiral nanoparticles/ lewis acids as cooperative catalysts for asymmetric 1,4-addition of arylboronic acids to $\alpha, \beta$-unsaturated amides. Angew. Chem. Int. Ed. 55, 8058-8061 (2016).

47. Mazet, C. \& Jacobsen, E. N. Dinuclear $\{($ salen $) \mathrm{Al}\}$ complexes display expanded scope in the conjugate cyanation of $\alpha, \beta$-unsaturated imides. Angew. Chem. Int. Ed. 47, 1762-1765 (2008).

48. Chea, H., Sim, H.-S. \& Yun, J. Copper-catalyzed conjugate addition of diboron reagents to $\alpha, \beta$-unsaturated amides: highly reactive copper-1,2- bis (diphenylphosphino)benzene catalyst system. Adv. Synth. Catal. 351, 855-858 (2009).

49. Molander, G. A., Wisniewski, S. R. \& Hosseini-Sarvari, M. Synthesis and Suzuki-Miyaura cross-coupling of enantioenriched secondary potassium $\beta$ trifluoroboratoamides: catalytic, asymmetric conjugate addition of bisboronic acid and tetrakis(dimethylamino)diboron to $\alpha, \beta$-unsaturated carbonyl compounds. Adv. Synth. Catal. 355, 3037-3057 (2013).

50. Hirsch-Weil, D., Abboud, K. A. \& Hong, S. Isoquinoline-based chiral monodentate N-heterocyclic carbenes. Chem. Commun. 46, 7525-7527 (2010).

51. Kobayashi, S., Xu, P., Endo, T., Ueno, M. \& Kitanosono, T. Chiral copper(II)catalyzed enantioselective boron conjugate additions to $\alpha, \beta$-unsaturated carbonyl compounds in water. Angew. Chem. Int. Ed. 51, 12763-12766 (2012).

52. Kitanosono, T., Xu, P. \& Kobayashi, S. Heterogeneous versus homogeneous copper(II) catalysis in enantioselective conjugate-addition reactions of boron in water. Chem. Asian J. 9, 179-188 (2014).

53. Gao, T.-T., Zhang, W.-W., Sun, X., Lu, H.-X. \& Li, B.-J. Stereodivergent synthesis through catalytic asymmetric reversed hydroboration. J. Am. Chem. Soc. 141, 4670-4677 (2019).

54. Bai, X.-Y., Zhao, W., Sun, X. \& Li, B.-J. Rhodium-catalyzed regiodivergent and enantioselective hydroboration of enamides. J. Am. Chem. Soc. 141, 19870-19878 (2019)

55. Wang, Z.-X. \& Li, B.-J. Construction of acyclic quaternary carbon stereocenters by catalytic asymmetric hydroalkynylation of unactivated alkenes. J. Am. Chem. Soc. 141, 9312-9320 (2019).

56. Wang, Z.-X., Bai, X.-Y. \& Li, B.-J. Metal-catalyzed substrate-directed enantioselective functionalization of unactivated alkenes. Chin. J. Chem. 37, 1174-1180 (2019).

57. Evans, D. A. \& Fu, G. C. Conjugate reduction of.alpha.,.beta.-unsaturated carbonyl compounds by catecholborane. J. Org. Chem. 55, 5678-5680 (1990).

58. Leutenegger, U., Madin, A. \& Pfaltz, A. Enantioselective reduction of $\alpha, \beta$ unsaturated carboxylates with $\mathrm{NaBH} 4$ and catalytic amounts of chiral cobalt semicorrin complexes. Angew. Chem. Int. Ed. Engl. 28, 60-61 (1989).

59. Smith, S. M., Thacker, N. C. \& Takacs, J. M. Efficient amide-directed catalytic asymmetric hydroboration. J. Am. Chem. Soc. 130, 3734-3735 (2008).

60. Smith, S. M. \& Takacs, J. M. Amide-directed catalytic asymmetric hydroboration of trisubstituted alkenes. J. Am. Chem. Soc. 132, 1740-1741 (2010).

61. Liu, Z., Ni, H. Q., Zeng, T. \& Engle, K. M. Catalytic carbo- and aminoboration of alkenyl carbonyl compounds via five- and six-membered palladacycles. $J$. Am. Chem. Soc. 140, 3223-3227 (2018).

62. Wang, G. et al. Iridium-catalyzed distal hydroboration of aliphatic internal alkenes. Angew. Chem. Int. Ed. 58, 8187-8191 (2019).

63. Bai, Z. et al. Palladium-catalyzed amide-directed enantioselective carboboration of unactivated alkenes using a chiral monodentate oxazoline ligand. ACS Catal. 9, 6502-6509 (2019).
64. Dang, T. P. \& Kagan, H. B. The asymmetric synthesis of hydratropic acid and amino-acids by homogeneous catalytic hydrogenation. J. Chem. Soc. D. 481 (1971).

65. Huang, Z. et al. Arene $\mathrm{CH}-\mathrm{O}$ hydrogen bonding: a stereocontrolling tool in palladium-catalyzed arylation and vinylation of ketones. Angew. Chem. Int. Ed. 52, 4906-4911 (2013).

66. Chen, L., Yang, Y., Liu, L., Gao, Q. \& Xu, S. Iridium-catalyzed enantioselective a-C(sp3)-H borylation of azacycles. J. Am. Chem. Soc. 142, 12062-12068 (2020).

\section{Acknowledgements}

This work was supported by the National Natural Science Foundation of China (Grant No. 21971139 and 22022104).

\section{Author contributions}

T.-T.G. discovered the reaction and optimized the reaction conditions. T.-T.G., H-.X.L and P.-C.G. investigated the scope of the substrate. T.-T.G. conducted the DFT calculation. B.-J.L. directed the project and wrote the manuscript with input from all of the authors.

\section{Competing interests}

The authors declare no competing interests.

\section{Additional information}

Supplementary information The online version contains supplementary material available at https://doi.org/10.1038/s41467-021-24012-z.

Correspondence and requests for materials should be addressed to B.-J.L.

Peer review information Nature Communications thanks Jiefeng Hu and Zhuangzhi Shi for their contribution to the peer review of this work.

Reprints and permission information is available at http://www.nature.com/reprints

Publisher's note Springer Nature remains neutral with regard to jurisdictional claims in published maps and institutional affiliations.

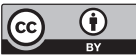

Open Access This article is licensed under a Creative Commons Attribution 4.0 International License, which permits use, sharing, adaptation, distribution and reproduction in any medium or format, as long as you give appropriate credit to the original author(s) and the source, provide a link to the Creative Commons license, and indicate if changes were made. The images or other third party material in this article are included in the article's Creative Commons license, unless indicated otherwise in a credit line to the material. If material is not included in the article's Creative Commons license and your intended use is not permitted by statutory regulation or exceeds the permitted use, you will need to obtain permission directly from the copyright holder. To view a copy of this license, visit http://creativecommons.org/ licenses/by/4.0/.

(C) The Author(s) 2021 